\title{
Refining intervention: The acquisition of featural relations in object A-bar dependencies
}

The presence of a [+NP] feature (representing a 'lexical restriction') on both the moved DP and the intervening subject is assumed to hinder children's comprehension of object A-bar dependencies (Friedmann et al. 2009). In order to better understand the nature and impact of this feature and its interaction with animacy, we assessed comprehension of object relative clauses and wh-questions in French-speaking children aged 5 to 11 using a character-selection task. Furthermore, we explored the link between processing of featural relations and working memory abilities through digit-span tasks. Results on questions straightforwardly confirm the role of the [+NP] feature; results on relatives suggest that the locality effect is sensitive to the formal similarity in D+NP shape of the target and the intervener. An animacy mismatch facilitates processing (as of age 7) only in the [+NP] condition, suggesting that the computation of locality draws on the structural expression of features, not just their mere semantic value. We argue in favor of a restrictive structural approach to intervention, and of a hierarchical organization of features. The link between accuracy and memory scores illustrates that limitations of computational resources affect processing of A-bar dependencies.

Keywords: Language acquisition; Wh-questions; Relative Clauses; Animacy; Locality; Working Memory

\section{Background}

A consistent finding for the acquisition of $A^{\prime}$-dependencies (wh-questions and relative clauses henceforth RCs) is that children find headed object dependencies harder to process than subject dependencies (Avrutin, 2000, de Villiers et al., 1994, Goodluck \& Tavakolian, 1982, for English; Corrêa, 1995, Costa et. al, 2011, for Portuguese; Arnon, 2005, 2010, Friedmann \& Novogrodsky, 2004, for Hebrew; Adani et al., 2010, Adani, 2011, Arosio, Adani \& Guasti, 2011, for Italian). Grammatical accounts explain children's problems with certain movement configurations in terms of intervention effects due to moving the object across a subject sharing morphosyntactic features (Friedmann et al., 2009), along the lines of the locality principle of Relativized Minimality (RM) operative in adult grammar (Rizzi, 1990, 2004, 2013; Starke, 2001). This principle states that a local relation between $X$ and $Y$ cannot hold if there is an intervener, $Z$, which is of the same structural type as $X$ and which can be a potential candidate for the relation.

(1)

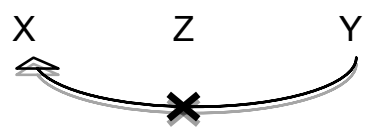

(C) 2015. This manuscript version is made available under the Elsevier user license http://www.elsevier.com/open-access/userlicense/1.0/ 
Based on the observation that children only struggle with object RCs and wh-questions headed by a full NP, Friedmann et al. (2009) capture the difficulty in processing these A'-dependencies in terms of the locality principle of RM and identify the [+NP] feature (which indicates the presence of a lexical restriction) as the source of intervention effects. The authors assume that the child system, endowed with weaker computational capacities, is not able to distinguish between the features of the moved $A^{\prime}$ object and the intervening subject when they are both [+NP]. The intervener thus blocks the local A'relation connecting the target and its trace, as illustrated in (2) for headed object RCs and in (3) for which $N P$ object questions $([+\mathrm{R}]$ and $[+\mathrm{Q}]$ are the scope-discourse or 'criterial' features attracting the target to the corresponding $A^{\prime}$-position):

$$
+\mathrm{R} \mathrm{NP} \quad+\mathrm{NP} \quad<+\mathrm{R} N \mathrm{NP}
$$

(2) Show me the lady [that the girl is kissing $<$ the lady $>1$ ].

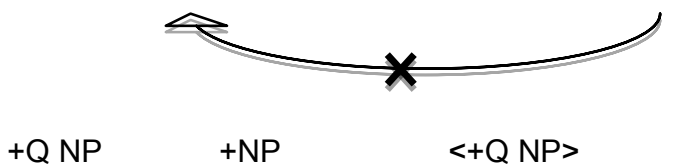

(3) Which lady [is the girl kissing $<$ the lady $>$ ].

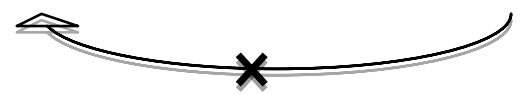

The RM approach predicts higher accuracy for subject RCs (4a) and wh-questions (4b). In these sentences, no Z-type element intervenes between the relative head or the wh-element and its trace in the subject position. Moreover, RM predicts better accuracy for object dependencies such as free RCs (5a) and bare wh-questions (5b) in which the moved element and the intervener $Z$ have different featural specifications:

$$
+\mathrm{R} N \mathrm{NP} \quad+\mathrm{R} N \mathrm{P}
$$

(4) a. Show me the girl [that $<$ the girl $>$ is kissing the lady].

$$
+Q N P \quad+Q N P
$$

b. Which girl [<which girl $>$ is kissing the lady]?

$$
+\mathrm{R} \quad+\mathrm{NP} \quad<+\mathrm{R}>
$$

(5) a. Show me who [the girl is kissing $<$ who $>$ ].

$+\mathrm{Q} \quad+\mathrm{NP} \quad<+\mathrm{Q}>$

b. Who [is the girl kissing $<$ who $>$ ]

The difference between children and adults stems, in this approach, from the hypothesis that child and

\footnotetext{
1 We assume Chomsky's (1995) Copy Theory of Traces, which postulates that traces are full (unpronounced) copies of their antecedents.
} 
adult grammars have different cut-off points in an otherwise identical locality system, based on RM expressed in terms of the featural specifications of the target and the intervener and of their set-theoretic relations. Whereas adult grammar only rules out configurations that involve an identity of the relevant morphosyntactic features between the target $X$ and the intervener $Z$, i.e. when the two share identical sets of features, children also struggle with configurations that express an inclusion relation. In the case of headed object RCs and wh-questions, this is due to the NP feature overlapping between the moved element and the intervener. Immature systems are only able to compute configurations in which the moved A'-object and the embedded subject differ maximally. As a result, they perform considerably better with those dependencies headed by a bare [-NP] element as in (5), because these display a disjunction relation between the relevant featural specifications of the two elements.

However, if [NP] is considered to be a feature in the grammar, along the lines of the RM approach outlined above, then the natural question to ask is whether other morphosyntactic features modulate comprehension of $A^{\prime}$-dependencies. This is particularly relevant in light of recent studies which have revealed that features such as number and gender modulate comprehension of headed A'dependencies. More specifically, a mismatch in these features facilitates processing of $A^{\prime}$-structures, although the effects surface to different degrees from language to language. In Italian, for example, a number mismatch between the moved element and the intervener improves performance, whereas a gender mismatch does not (Adani et al., 2010). On the other hand, a gender mismatch does have an impact in Hebrew (Belletti et al. 2012). Based on the selective effect of gender in Hebrew and Italian, these authors postulate an enrichment of RM effects present in child grammar, by adding another set theoretic relation, intersection, along the lines of (6):

(6)

\begin{tabular}{llll}
\multicolumn{1}{c}{$\boldsymbol{x}$} & & $Z$ & \multicolumn{2}{c}{$Y$} \\
Identity & A & A \\
Inclusion & A,B & B \\
Non-inclusion: Intersection & A,C & C,D \\
Non-inclusion: Disjunction & A & B
\end{tabular}

\begin{tabular}{|c|c|c|c|c|}
\hline Target & & Intervener & Trace & \\
\hline$x$ & $Z$ & $Y$ & Adults & Children \\
\hline A & & $A$ & $<A>$ & * \\
\hline$A, B$ & & $B$ & $<A, B>$ & ok \\
\hline$A, C$ & & $C, D$ & $<\mathrm{A}, \mathrm{C}>$ & ok \\
\hline$A$ & & $B$ & $<A>$ & ok \\
\hline
\end{tabular}

(adapted from Belletti et al., 2012)

The claim is that the child system performs better on non-inclusion configurations. More specifically, in the system above, children are able to compute not only disjunction, but also intersection relations, in which the intervener differs from the target in at least one 'relevant' feature. A feature is relevant in a given language when it is syntactically 'active' in the sense that it belongs to the feature set triggering movement. This would be the source of the cross-linguistic difference attested between Hebrew and Italian: a salient morphosyntactic difference between the two languages is that gender is morphologically expressed on the inflected verb in Hebrew but not in Italian, a morphological difference to be plausibly 
interpreted as the overt manifestation of the fact that gender belongs to the set of Phi features attracting a DP to subject position in Hebrew but not in Italian. If only features participating in the triggering of movement are taken into account in the calculation of RM, this difference accounts for the lack of an effect of gender mismatch on the comprehension of RCs in Italian-speaking children. Pursuing this line of reasoning, it becomes evident why number does impact processing in Italian since, unlike gender, number acts as an attractor for movement in this language.

As far as the animacy feature is concerned, a range of studies has shown that it plays a role in the comprehension of complex structures, both for adults and children. The difference between subject and object RCs disappears when the object is inanimate and the subject is animate (Mak et al., 2002, 2006; Traxler et al. 2002; Baudiffier et al., 2011). Object relatives with an inanimate head and an animate subject also seem to be the most frequent type of object RCs found in naturalistic corpora (Mak et al. 2002 for Dutch and German; Belletti and Chesi 2011 for Italian). However, Belletti and Chesi (2011) show that this frequency in the input does not correlate with performance in experimental conditions: their results from an elicited production experiment with Italian-speaking adults revealed that an animacy match or mismatch between the head of the relative and the internal RC subject did not favor the production of object relatives. Concerning children's comprehension of object RCs, some studies indicate that it is influenced by a mismatch in animacy between the arguments of the verb, which seems to facilitate theta-role assignment when the object DP is inanimate and the embedded subject is animate. In these contexts, children find it easier to identify which nominal is the agent and which is the patient of the action, as revealed by improved performance for ORs headed by an inanimate DP2 (Corrêa 1995, Brandt et al. 2009, Arosio et al. 2010). Children's performance changes in the case of object RCs with an animate object and an inanimate embedded subject. Adani (2012) reports that such a mismatch in animacy does not facilitate comprehension of object RCs in an experiment with 4- and 5year-old German-speaking children and therefore concludes that dissimilarity in the Animacy feature per se does not improve comprehension of object RCs. So, although there are indications that animacy may influence the comprehension process in children, there is an ongoing debate of how exactly it affects comprehension, and how it relates to the use of other properties such as structure type and morphosyntactic information.

These findings regarding the role of animacy, coupled with the RM approach to children's difficulties with headed object A'-dependencies, give rise to a number of further questions: How is the [+NP] specification to be understood exactly? What is the role of animacy? Does an animacy mismatch between the target and the intervener give rise to an intersection configuration in the sense of Belletti et

\footnotetext{
2 Kidd et al. (2007) also point out that the animacy of the object RC head strongly influences both the frequency with which English and German children produce these structures in spontaneous speech and the successful repetition of $R C$ sentences in an experimental setting.
} 
al. (2012), thus improving comprehension? If so, what makes animacy a 'relevant' feature for the computation of RM? Does the way in which animacy is expressed in the structure matter? Moreover, if the key property of the problems that children experience with certain object A-bar dependencies resides in the difficulty to calculate the inclusion relation, we may expect this difficulty to correlate with measurable limitations of children's working memory. Does it?

\section{Our study}

In this study we aim to refine the characterization of the [+NP] feature and of its additional subspecifications that RM is sensitive to, with a special reference to the animacy feature. We intend to investigate the question in a comprehensive manner, both in terms of the constructions covered and the age range of the effects. As for the first point, we will investigate the comprehension of wh-questions and $\mathrm{RCs}$ in French by focusing on the manner in which these two constructions instantiate the [+NP] / [-NP] divide, as this interestingly modulates the relevant intervention configuration in ways that implicate the animacy specification as well. As for the second point, we will explore the effects in four age groups: 5 years, 7 years, 9 years and 11 years. This will allow us to get a systematic picture of the developmental curve.

Questions straightforwardly express the presence or absence of the lexical restriction, both in the animate (quelle fille vs qui in (7)) and inanimate (quelle balle vs que in (8)) paradigm:

(7) a. Quelle dame est-ce que la fille embrasse?

which lady ESK the girl kisses

'Which lady is the girl kissing?'

b. Qui est-ce que la fille embrasse?

who ESK the girl kisses

'Who is the girl kissing?'

(8) a. Quelle balle est-ce que la fille tape?

which ball ESK the girl hits

'Which ball is the girl hitting?'

b. Qu(e) est-ce que la fille tape?

What ESK the girl hits

'What is the girl hitting?'

Things are more complex for headed relatives, on the other hand. They involve non-lexical heads with the complex pronominal form celui-celle in the animate paradigm:

(9) a. Montre-moi la dame que la fille embrasse. 
show-me the lady that the girl kisses

'Show me the lady that the girl is kissing.'

b. Montre-moi celle que la fille embrasse.

show-me this/that+her that the girl kisses

'Show me the one that the girl is kissing.'

Celui/celle is naturally analyzable as ce+lui/ce+elle, i.e. a determiner ce plus a pronominal form lui/elle (as in Gross, 1978, Kayne, 2010, Kayne and Pollock, 2010) ${ }^{3}$, roughly analogous to English one, also following the determiner in the one that the girl is kissing, etc.. This allows us to address the question of whether the relevant factor making the relative head dissimilar from the intervening subject is (i) the lack of a lexical noun endowed with descriptive content (in which case (9b) should be understood significantly better than (9a)) or (ii) the mere formal (dis)similarity in D+NP shape between the head and the embedded subject, where the NP component can be a lexical form (fille) or a pronominal form (elle) and which entails that comprehension of $(9 a)$ and $(9 b)$, both with relative heads structured as $D+N P$, should be roughly on a par.

In the case of the RC headed by a pronominal form, there is a further interesting twist which involves animacy: an animate head necessarily has the complex shape celui/celle, whereas an inanimate head can have the simple shape $c e^{4}$, plausibly analyzable as a bare determiner, hence just $D$, not $D+N P$ :

(10) a. Montre-moi la balle que la fille tape.

show-me the ball that the girl hits.

'Show me the ball that the girl is hitting.'

b. Montre-moi ce que la fille tape.

show-me what that the girl hits.

'Show me what the girl is hitting.'

\footnotetext{
3 Interestingly, these elements cannot stand alone: when they are not followed by a RC as in (i), they obligatorily cooccur with a deictic element, shown in (ii).

(i) Voilà deux robes. *Décris-moi celle. here two dresses. describe-me this/that+her.

(ii) Voilà deux robes. Décris-moi celle-là/ celle-ci. here two dresses. describe-me this/that+her-there/this/that+her-here.

'Here are two dresses. Describe to me that one/ this one.'

${ }^{4}$ As evidenced by example (ii) in the preceding footnote, celle/celui can also refer to inanimate antecendents (e.g. la robe 'the dress'). However, given that we also wanted to compare +NP constituents with unequivocally -NP elements (along the lines of the +NP/-NP comparison in wh-questions), we opted for the use of ce as the inanimate counterpart of celui/celle in the present experimental design.
} 
The inanimate paradigm in RCs directly instantiates the $[ \pm N P]$ divide, much like in the case of questions (as in (8)). As for the animate paradigm, we adopt the terminology of previous studies (Friedmann et al., 2009, Belletti et al., 2012) where the +NP feature characterized cases involving the presence of a lexical noun and, accordingly, we initially classify relatives headed by celui/celle as -NP.

To summarize:

(i) Questions are structurally more uniform, and allow us to directly assess the role of the [ \pm NP] distinction, as in (7)-(8).

(ii) They also allow us to directly address the role of the animacy specification in both the +NP and $-\mathrm{NP}$ condition, as in (7) vs (8).

(iii) Relatives are structurally more varied, instantiating the case of a D+NP form with a nominal pro-form in the animate paradigm, a case which allows us to disentangle pure formal (dis-) similarity in the D+NP shape from presence vs absence of lexical restriction with descriptive content.

(iv) Relatives in the inanimate paradigm are akin to questions, and instantiate the simple [ $\pm N P]$ dissociation, as in (10).

\subsection{Links with Working Memory}

The observation that certain $A^{\prime}$-dependencies emerge at a later stage is of particular interest to our study. If grammatical competence is essentially in place early on in a child's development as has been argued by proponents of the Strong Continuity Hypothesis (see Atkinson 1996; Hyams 1996), then the fact that these structures take longer to be consolidated suggests that the particular resources recruited for computing such structures develop late. One plausible line to investigate concerns memory resources: it could be that specific types of movement are difficult for young children because the complex computation of the subset-superset relation between target and intervener requires rich memory resources, initially not available to the child. One aim of the present study is thus to investigate the potential link between children's working memory (WM) resources and their accuracy at computing featural relations in A'-configurations. As such, this work joins a growing body of research testing the extent to which WM is predictive of children's ability to comprehend and produce complex syntactic structures.

Several studies have investigated the role of WM processes and children's comprehension of RCs ${ }^{5}$, but

\footnotetext{
5 It is interesting to note that links between complex syntax and WM are observable in adults: experimental studies with adults point to a relation between WM capacities and RC comprehension, as evidenced by slower reading times at the main verb for object RCs in adults with low reading spans, as compared to adults with a high reading span (King and Just 1991). Using fMRI investigations, Santi \& Grodzinsky (2007) reveal that the parsing of
} 
the findings are mixed. Booth, MacWhinney, and Harasaki (2000) report that the forward digit span task interacted with reading and listening times and with accuracy measures for both subject and object center-embedded RCs in 8- to 12-year-old English-speaking children. Arosio, Guasti, and Stucchi (2011) also observe that 9-year-old Italian children's performance on the forward digit span task predicted the offline comprehension of object RCs, although they did not find the same effect for online processing. Moreover, these authors found no effect of listening span on children's comprehension of RCs, both in the offline and online tasks. Boyle, Lindell, and Kidd (2013) also observe an interaction between 4;6- to 6;6-year-old English children's comprehension of object RCs and a sentence repetition task, but no interaction with backward digit-span scores.

In our study, we extend the scope of the structures investigated so far in relation to WM by comparing RCs and wh-questions and by testing children from a wide age-range (5 to 11 years old) with the goal of determining when the computational resources available to children approach those of adults and how this affects comprehension of $A^{\prime}$-dependencies. In this study, we adopt the best-established model of WM in children, Baddeley's (2007) multiple component model of WM. According to this model, WM is a system of limited capacity which temporarily stores and manipulates information and which consists of several subcomponents (i) the phonological loop, (ii) the central executive, and (iii) the episodic buffer. The role of the phonological loop is twofold: it stores incoming memory traces of phonological information for a few seconds and then rehearses information so as to revive memory traces. The capacity of the phonological loop is limited and is commonly measured by having participants recall various types of lists. The central executive is responsible for directing and controlling the information stored in the phonological loop. Its capacity is also limited and is usually assessed through tasks that involve both retaining and manipulating information. The episodic buffer is a recent addition to the WM model (Baddeley 2000). The role of this latter component of WM is to store, for a short period of time, chunks of information that have been integrated from other memory subsystems.

For the purpose of this study, we have used two digit span tasks as measures for the phonological loop and central executive capacities of the WM system. The forward digit span is a measure of phonological short-term memory resources. The task requires participants to maintain, in the phonological loop, the correct order of an increasing sequence of digits and to repeat it. In the case of the backward digit span, participants also have to manipulate the retained information by calculating the reversed order of the digits. This makes the backward digit span a suitable measure of central executive functioning, as it implies retaining, manipulating, and recalling a given number sequence.

movement structures such as RCs interacts closely with the activation of a section of Broca's area which appears to be involved in syntactically specialized WM. 
When parsing object A'-dependencies, one has to retain information about the head of the dependency until the gap position is encountered. At this point, the processing system must be able to effectively retrieve the corresponding noun phrase from memory, despite the elements and the interpretive processes that intervene between the moved item and its base position (see Gibson 1998; Grodner and Gibson 2005; Lewis and Vasishth 2005; Van Dyke and McElree 2006 for studies with adults). This sort of cognitive manipulation might pose problems to immature cognitive systems and be more readily accessible to systems with higher computational resources (Booth et al. 2000). Consequently, if the computation of featural relations builds not only upon grammatical abilities, but also on other cognitive capacities such as working memory, then we should observe a link in our study between successful processing of these relations and increased working memory resources.

\section{Experiment}

With this experimental investigation, we thus aim to test (i) how minimality effects are modulated by the nature and properties of a lexical NP feature; (ii) whether features like animacy modulate comprehension; (iii) whether these features have a similar impact across A'-structure types and age groups; (iv) whether the computation of featural relations draws upon working memory abilities.

\subsection{Subjects}

A total of 61 typically developing French-speaking children from two primary schools in Geneva, Switzerland, were recruited for this study. They were divided across four age groups, as shown in Table 1. Each child was tested separately in a quiet room. No time constraint was imposed during testing and children were rewarded at the end of the session.

\section{Table 1}

Participants

\begin{tabular}{|c|c|c|c|c|}
\hline Age Group & Total Nr. & Age Range & Mean Age & SD \\
\hline 5 & 14 & $4 ; 9-5 ; 9$ & $5 ; 2$ & $0 ; 3$ \\
\hline 7 & 17 & $6 ; 7-7 ; 5$ & $7 ; 0$ & $0 ; 3$ \\
\hline 9 & 16 & $8 ; 7-10 ; 0$ & $9 ; 1$ & $0 ; 5$ \\
\hline 11 & 14 & $10 ; 9-11 ; 10$ & $11 ; 2$ & $0 ; 3$ \\
\hline
\end{tabular}

3.2. Materials and Method 
We tested 12 object wh-questions and 12 object relative clauses ${ }^{6}$, divided across a $2 \times 2$ design with LEXICAL RESTRICTION (+NP, -NP7) and OBJECT ANIMACY (+Animate, -Animate) as independent factors. We illustrate below the levels along which we varied wh-questions (Table 2) and RCs (Table 3), together with the corresponding examples:

\section{Table 2}

Experimental conditions: Wh-questions

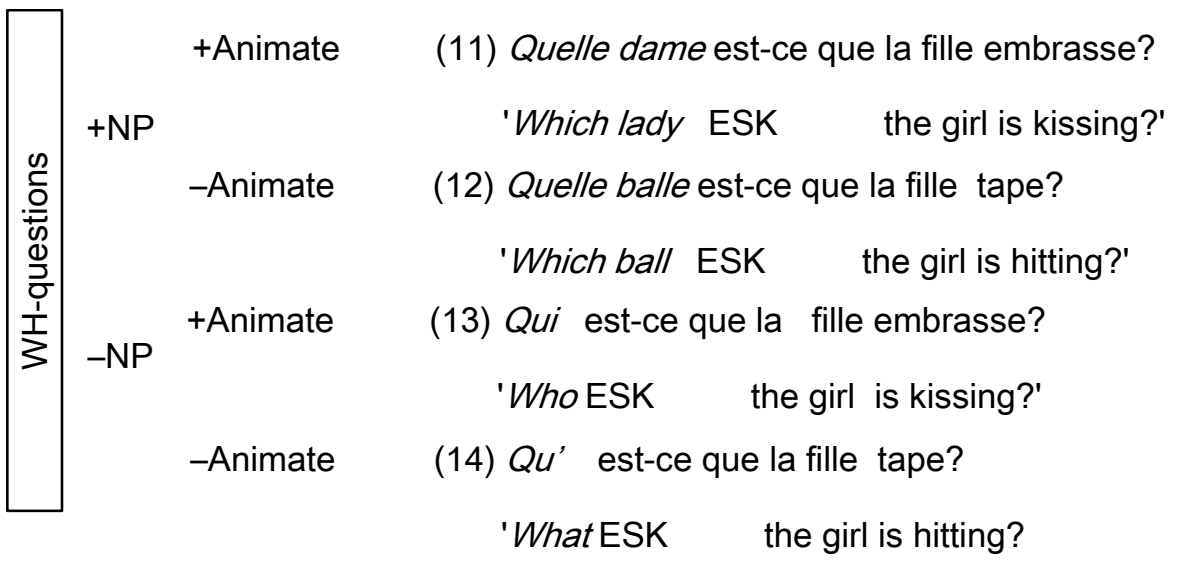

Table 3

Experimental conditions: Relative Clauses

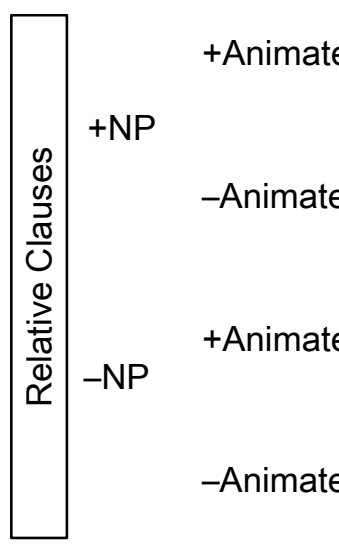

(15) Montre-moi la dame que la fille embrasse.

'Show me the lady that the girl is kissing.'

(16) Montre-moi la balle que la fille tape.

'Show me the ball that the girl is hitting.'

(17) Montre-moi celle que la fille embrasse.

'Show me the one that the girl is kissing.'

(18) Montre-moi ce que la fille tape.

'Show me what that the girl is hitting.'

\footnotetext{
${ }^{6}$ Various studies (Avrutin 2000; Friedmann et al. 2009, etc.) have already shown that subject lexically-restricted dependencies yield better performance as compared to object lexically-restricted dependencies (which is precisely what an account in terms of RM predicts). Hence we do not specifically explore the subject/object asymmetry in this paper.

${ }^{7}$ Here we intend +NP to refer to the presence of a nominal element drawn from the substantive lexicon; as such, in the initial classification of the stimuli, -NP designates both RCs with complex pronominal heads like Montre-moi celle que la dame embrasse, and RCs headed by bare determiners like Montre-moi ce que la fille frappe.
} 
Comprehension of wh-questions and RCs was assessed using a character selection task, an adapted version of the task employed in Friedmann et al. (2009). Figure 1 shows examples of pictures used in the experiment. Each picture depicted the same action performed twice with reversed Agent-Patient roles. The actual experiment was preceded by a warm-up task aimed at familiarizing children with the characters and with precise pointing. The warm-up started with a simple pointing task in which children saw various pictures and had to find and show the specific character or object named by the experimenter as in, for example Where can you see a grasshopper?. This was followed by four practice trials, which included pictures similar to those used in the experimental trials. The experimenter explained to the children that they would see two images at a time and that they would have to point to the correct character/object in one of these images. Moreover, the experimenter drew children's attention to the fact that they should choose and point out only one of the four possible options given in the images. If children's responses were ambiguous (e.g. pointing to the whole image), the experimenter would pretend that she did not pay attention and would ask the child to identify again the precise character/object. However, this happened very seldom as children were very eager to point to only one character/object. During the test phase, the experimenter first gave the child a short lead-in: "Look! There are two girls and two ladies in this picture!". This was then followed by either a RC or a whquestion prompting participants to choose the correct character out of 4 possible options. Given that we only tested object dependencies, the target answer for all the experimental items consisted of pointing to the patient of the action expressed by the verb. Each test sentence was used only once and was associated with a picture which depicted either four animate characters for the animacy match condition (figure (1a) or two animate characters and two objects for the animacy mismatch condition (figure (1b)) 8 :

\footnotetext{
${ }^{8}$ As noted by an anonymous reviewer, one potential drawback of our experiment is the use of a slightly infelicitous context (e.g. Which lady is the girl kissing? paired with a picture in which there are two girls). Our pictorial stimuli replicated the format of other experiments in the literature (see for example Friedmann et al. (2009) who also tested comprehension of relative clauses using two pictures with 4 characters). Given that we used a character-selection task, contrary to Friedmann et al. who used an image-selection task, and that children had to point to a specific character and not to an entire image, we wanted to distinctly represent all the characters in the pictures. If pragmatics had influenced children's answers, we would have expected this to impact results across the various conditions tested. However, our findings show that this is not the case.
} 


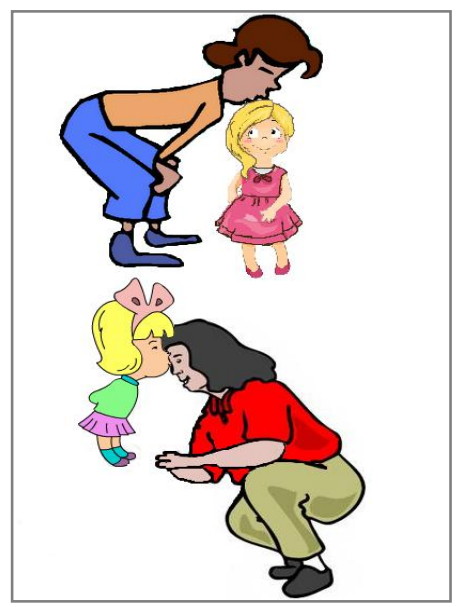

a. Animacy match

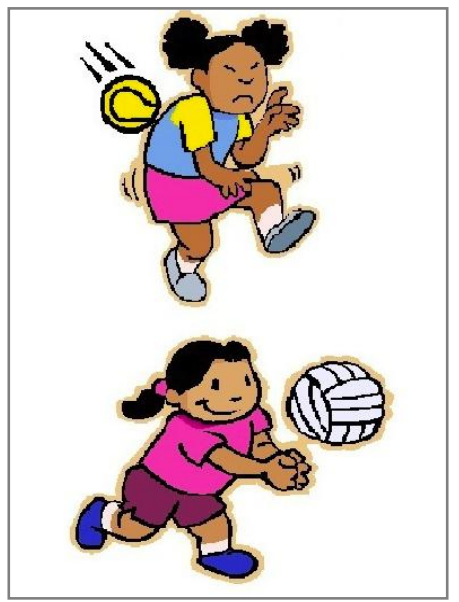

b. Animacy mismatch

Fig. 1. Pictures used in the character-selection task

All the items contained transitive verbs, as well as two noun phrases matched for number (always singular) and for gender. Half of the nouns used were masculine, half were feminine. The position of the correct character was counterbalanced between the four possible positions. In addition, the target character/object did not appear in the same position on the page (top or bottom) in consecutive trials and there were no two consecutive pictures depicting the same action. The 24 test sentences were randomized across two different lists and were interspersed with 16 fillers (sentences such as "Touch the duck with the ice-cream.") used in order to maintain children's interest and ensure that they remained attentive throughout the task. Consequently, each child saw a total of 40 sentences and the experiment lasted approximately 20 to 25 minutes.

Alongside comprehension of A'-dependencies, verbal short-term memory was assessed through a standardized digit span task taken from the Wechsler Intelligence Scale for Children (WISC IV, Wechsler 2005). The task consisted of orally presenting the participants with a series of digits increasing in length from 2 to 9 . Children were asked to listen carefully to the series of digits and immediately repeat them aloud, either in the same order (yielding the forward digit span) or in the reversed order (yielding the backward digit span). The length of the longest list a participant can remember is their overall digit span. The task was stopped when children missed 2 out of 2 trials within one level.

\section{Results}

The dependent measure in our character selection task was response accuracy. An answer was coded as correct if the child chose the right Patient out of four competitors within each set of pictures. Consequently, the chance level is considered to be $25 \%$. We first present the overall results for whquestions and relative clauses, by looking at the effect of both the $[ \pm N P]$ and the $[ \pm$ Animate] distinction. 
The error bars in all the figures represent the standard error to the mean. We then describe the results for the working memory tasks.

\subsection{Comprehension task}

For questions, what determines the status of a wh-phrase as + or -NP is straightforward (quelle fille vs $q u I)$ and we see that children across all the age groups tested comprehended -NP questions crossing a +NP subject more accurately than +NP questions (Fig. 2). When analyzing the effect of the match or mismatch in animacy on both +NP and -NP questions, we see a different sensitivity to animacy:

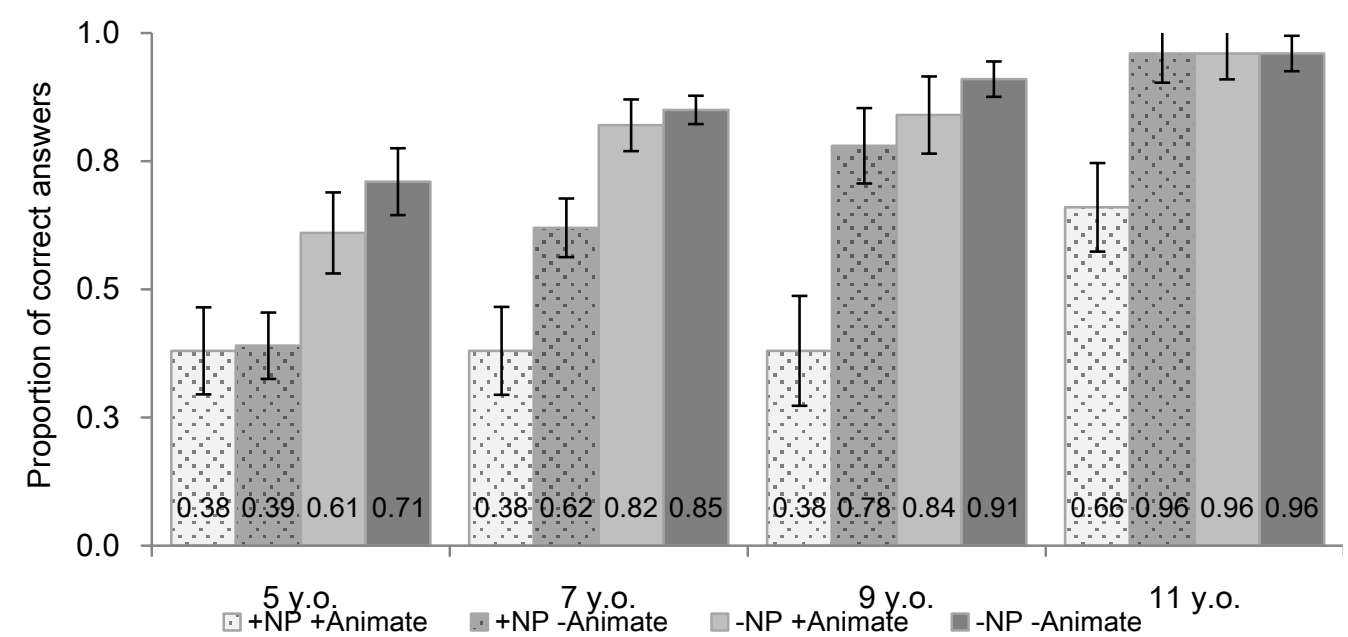

Fig. 2. Overall proportion of correct answers for object wh-questions with NP (+Animate 'quelle fille' / Animate 'quelle balle') and without NP (+Animate 'qui / - Animate 'que') in children from age 5 to 11

An animacy mismatch significantly improves the comprehension of questions in the +NP condition (i.e. Which ball is the girl hitting? is better understood than Which lady is the girl kissing?) in the 7, 9 and 11 year-old children, whereas no animacy effect is found in the 5 year-old group. On the other hand, the animacy mismatch in the -NP condition does not significantly improve comprehension in any group (i.e. response accuracy for What is the girl hitting? is on a par with that for questions like Who is the girl hitting?, in which the subject and the object match in animacy). These asymmetries in comprehension are also reflected in the number of children who performed above chance in the various experimental conditions. Whereas only 31 of 61 children performed above chance with object +NP wh-questions with two animate DPs, when the +NP wh-questions included an animacy mismatch, the number of children who performed above chance raised to 46. Performance improved in object - NP questions, with only 9 children performing below chance. The comprehension scores for wh-questions, when compared to a chance level of $25 \%$, shows that, overall, children performed above chance for these constructions. This suggests that children comprehend these structures, but find them harder than others which, in turn, leads to asymmetries in comprehension. 
Results are much less clear for relative clauses (Fig. 3) when we look at the results for the +NP and -NP conditions. For RCs with an inanimate head, like in the case of questions, it is also straightforward what determines the $[ \pm N \mathrm{NP}]$ status of the head noun (/a balle que...vs ce que...); for RCs with animate heads, we have initially counted relatives headed by celui/celle as -NP, under the initial assumption that the + NP value is given by the presence of a noun from the substantive lexicon.

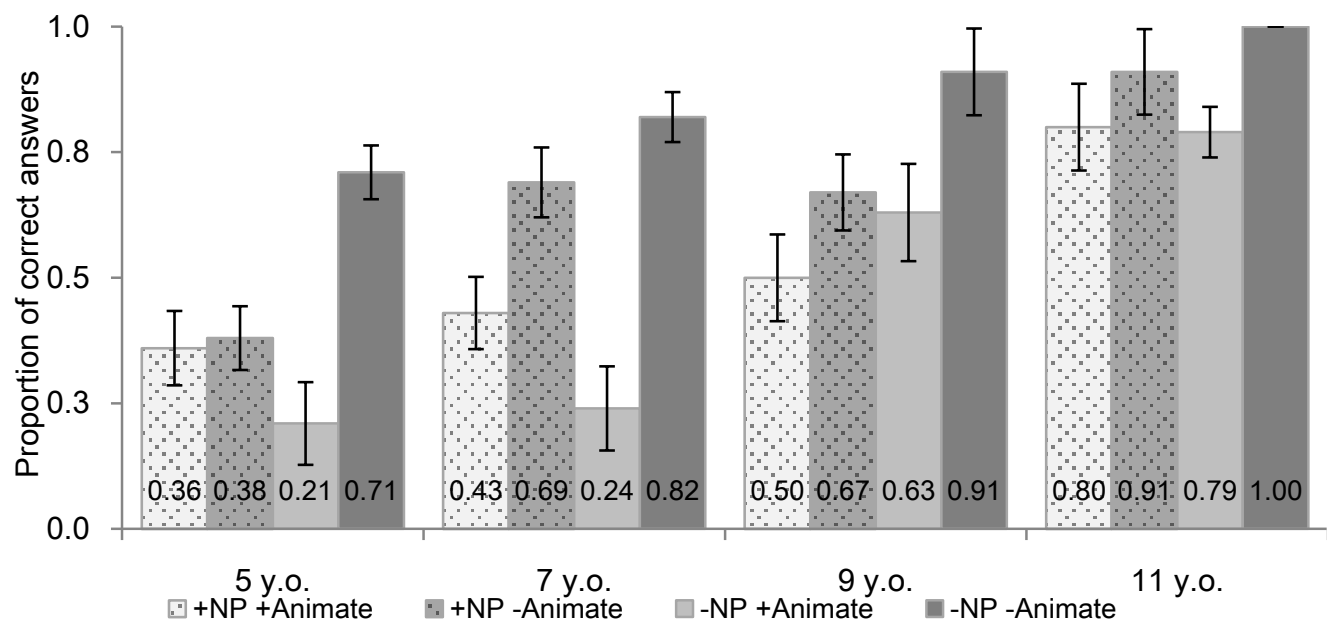

Fig. 3. Overall proportion of correct answers for object RCs with NP (+Animate '/a fille' / - Animate '/a balle') and without NP (+Animate 'celle' / - Animate 'ce') in children from age 5 to 11

If we look more closely at the results for RCs (Fig. 3) and compare +NP and -NP conditions by taking into account the match and mismatch in animacy, one important discrepancy between the RCs and questions emerges: -NP relatives with animate pronominal heads (Montre-moi celle que la fille embrasse.) yield lower accuracy scores across all age groups, which points to some special property of celuilcelle RCs. A total of 30 children perform below chance on -NP object relatives headed by celui/celle compared to 23 whose performance with +NP object relatives with an animate head is below chance. On the other hand, -NP RCs headed by inanimate objects (Montre-moi ce que la fille frappe.) lead to the highest accuracy scores for all age groups, in line with -NP inanimate questions. The contrast between animate and inanimate pronominally headed relatives (celuilcelle vs ce) thus represents the sharpest contrast in the experimental set. While celui/celle trials yield above chance performance only in the 9 year-old and the 11 year-old groups, all the other trials yielded above-chance performance in the four age groups tested. The 5- and 7-year-olds' chance performance with the celui/celle RCs indicate that the younger children struggle with these constructions, as their response patterns seem to be the result of guessing.

\subsection{Working memory}

The scores for the digit span tasks used to assess working memory illustrate that children perform better 
in the forward digit-span task (overall mean $=4.38$ ) than in the backward digit-span task (overall mean $=$ 2.83). Table 2 summarizes the performance means for each age group in the forward $d$-span and the backward d-span task. Children's forward d-span scores range from 3 to 6 (one of the 5 year-old children was not able to perform the task, two 5 year-olds only got a score of two, whereas the d-span of two children form the 9 and 11 year-old groups were as high as 7 and 9). As for the backward d-span, most of the 5 year-old children struggle with the task, their scores ranging as low as 0 and 2 . The other children's scores are in between 2 and 4, again with very few exceptions among the 11-year-old children (one child got a backward d-span score of 5 and two children got a score of 6 ).

Table 2

Performance means and standard deviation for the forward and backward d-span tasks by age group

\begin{tabular}{l|cc} 
Age Group & Mean Forward d-span (SD) & Mean Backward d-span (SD) \\
\hline 5 & $3.07(1.22)$ & $0.71(0.96)$ \\
\hline 7 & $4.17(1.04)$ & $2.88(0.67)$ \\
\hline 9 & $5.00(1.27)$ & $3.31(0.92)$ \\
\hline 11 & $5.00(1.00)$ & $3.71(0.96)$ \\
\hline
\end{tabular}

Participants with higher scores in the forward digit-span task also perform significantly better in the comprehension task. This is illustrated in Figure 4.A. The scores for the backward digit-span task (Figure 4.B.) suggest that better performance in the digit-backward test does not determine better response accuracy in children. This shows that performance on the backward test did not affect the performance on the comprehension task, in contrast with performance on the forward test.

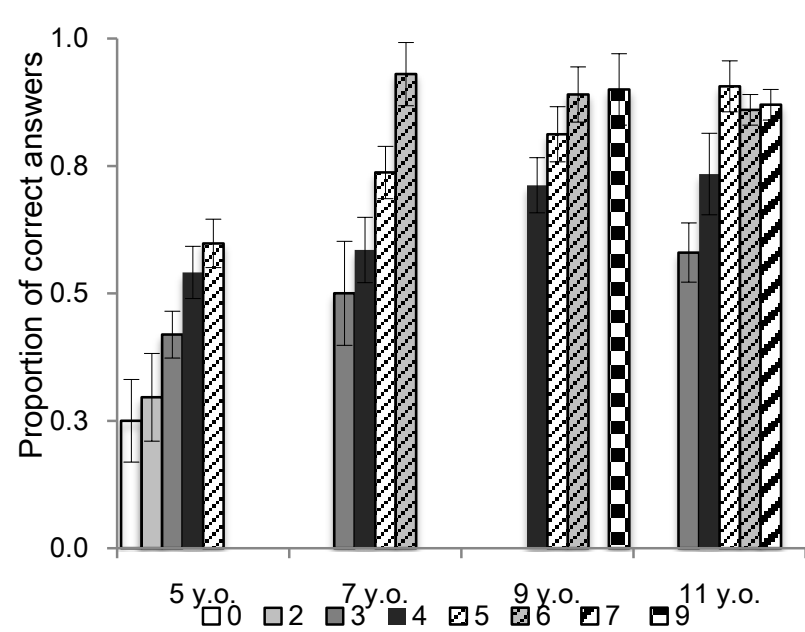

A. Forward D-span by Age Group

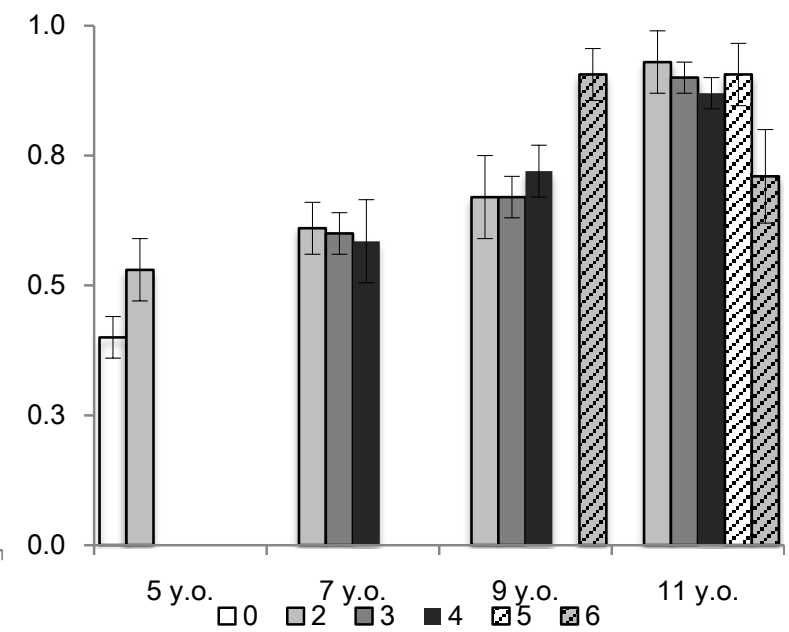

B. Backward D-span by Age Group

Fig. 4. Proportion of correct answers by Forward and Backward digit-span scores for each age group 


\subsection{Statistical analysis}

We fit our data with a mixed logit model (Baayen, Davidson, \& Bates, 2008; Jaeger, 2008) using the Ime4 package for Linear Mixed Effects (Bates, Maechler, Bolker, \& Walker, 2014) in R. Mixed logit models are well suited for the analysis of categorical response variables (Jaeger 2008) such as response accuracy in our study (i.e. pointing to the character identified as the correct Patient of the action). We consider wh-questions to be structurally more uniform whereas RCs to be structurally more varied in the way they express the +/-NP divide and therefore we carried out separate analyses for the two structures tested, using as fixed factors (i) Lexical Restriction and (ii) Object Animacy. Each factor was coded using a sliding contrast specification. This coding system takes the Grand Mean (or overall mean of the dependent variable) as intercept and the slopes indicate the differences between consecutive factor levels. -NP was the reference category for Lexical Restriction and +Animate was the reference category for Object Animacy. Age, Forward digit-span and Backward digit-span scores were included as continuous covariates in the models. Table 3 summarizes the results of the full final model for wh-questions. The final model was selected by first including all main effects and covariates, as well as interactions between main effects and covariates. We then removed predictors step by step and calculated the fit of the simpler model as compared to the more complex model (using a chi-square test based on the log likelihood ration statistics) until the fit of the simpler model was not significantly worse than the fit of the larger model. While the interaction of main effects with Forward digit-span scores $\left(\chi^{2}(1)\right.$ $=4.62, p=.59)$ and Backward digit-span scores $\left(\chi^{2}(1)=3.65, p=.56\right)$ was not significant, the interaction with Age adds significant information to the model $\left(\chi^{2}(1)=10.02, p<.01\right)$, as does the interaction between Lexical Restriction and Animacy $\left(\chi^{2}(2)=4.04, p<.05\right)$. The final full model is given in Table 3 , with number of observations and log-likelihood in the table caption.

\section{Table 3}

Fixed effect estimates for mixed logit model of correct answers for wh-questions (ResponseAccuracy LexicalRestriction * ObjectAnimacy * Age + (ForwardDspan + BackwardDspan $)+(1 \mid$ Participant $) ; \mathrm{N}=732, \mathrm{AIC}=$ $780.47, \mathrm{BIC}=831.03$, log-likelihood $=-379.24$ )

\begin{tabular}{lllll}
\hline Fixed effect & Coefficient & $S E$ & Wald $Z$ & $p$ \\
\hline (Intercept) & 0.33 & 0.48 & 0.68 & $>.4$ \\
Lexical Restriction $=-N P-+N P$ & 1.58 & 0.25 & 6.44 & $<.001^{* * \star}$ \\
Object Animacy = +Animate - -Animate & -0.87 & 0.24 & -3.57 & $<.001^{\text {** }}$ \\
Age & 0.03 & 0.007 & 3.94 & $<.001^{\text {}}$ \\
\hline
\end{tabular}




\begin{tabular}{lllll}
\hline Forward D-span & 0.25 & 0.10 & 2.46 & $<.02^{*}$ \\
Backward D-span & -0.09 & 0.12 & -0.73 & $>.4$ \\
Interaction = Lexical Restriction \& Object Animacy & 1.02 & 0.49 & 2.08 & $<.04^{*}$ \\
Interaction = Lexical Restriction \& Age & 0.002 & 0.010 & 0.17 & $>.8$ \\
Interaction = Object Animacy \& Age & -0.012 & 0.009 & -1.24 & $>.2$ \\
Interaction = Lexical Restriction \& Object Animacy \& Age & 0.03 & 0.005 & 1.63 & $>.1$ \\
\hline
\end{tabular}

The maximal random effect structure supported by the data included only random intercepts for participants. This is summarized in Table 4.

Table 4

Summary of random effects in the mixed logit model for wh-questions

\begin{tabular}{lll}
\hline Random effect & $\mathrm{s}^{2}$ & $\mathrm{SD}$ \\
\hline Participant Intercept & 0.25 & 0.50 \\
\hline
\end{tabular}

The mixed logit model for wh-questions revealed several main effects and one interaction as significant. In line with previous findings, the absence of lexical restriction (-NP) improves children's comprehension of object questions, as evidenced by the positive coefficient of Lexical Restriction. The negative coefficient for Object Animacy shows that performance is less accurate with object wh-questions with an animacy match between the subject and the object. The interaction between Lexical Restriction and Object Animacy (Figure 5) was also significant $(\beta=1.02$, $S E=0.49, z=2.08, p=<.04$ ), showing that Object Animacy has a different impact when coupled with -NP questions than when associated with +NP object questions: while Object Animacy affects performance on +NP trials, as children are more accurate with +NP -Animate than with +NP +Animate trials, children's performance on -NP trials is the same independently of Object Animacy. Age and Forward digit-span scores also have a significant effect on comprehension: older children and children with higher memory scores perform more accurately in the experimental task. There was no significant effect of backward digit-span ( $p>.05)$, nor a significant interaction between Object Animacy and Age or between Age and the two fixed factors (Lexical Restriction and Animacy) (all $p>$.05). 


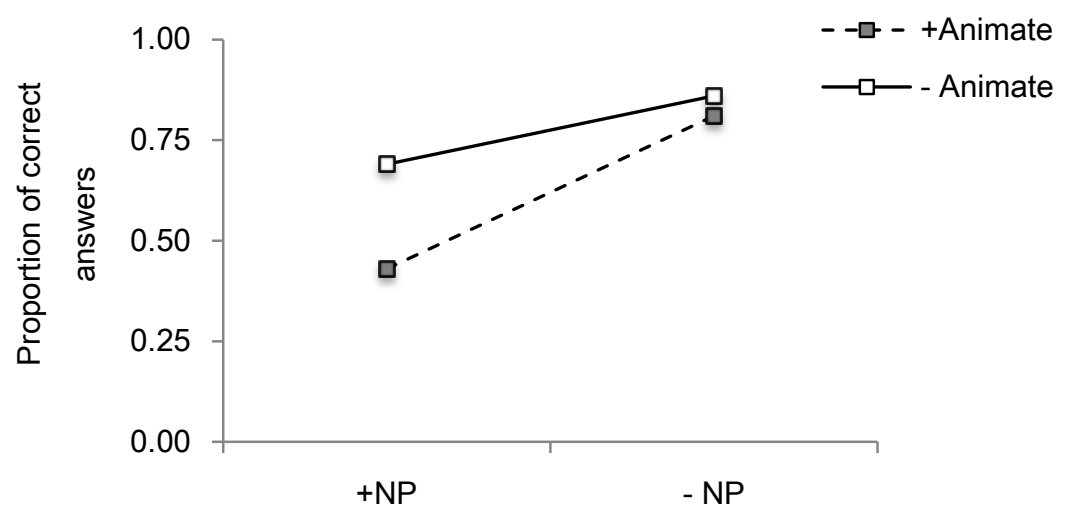

Figure 5. Overall proportion of correct answers for wh-questions as a function of lexical restriction (+/NP) and object animacy (+/-Animate) for all age groups

In order to answer our theoretical questions, we followed up on the interpretation of the interaction with pre-planned pairwise comparisons in which we analyzed the effect of Object Animacy on the two levels of Lexical Restriction (+NP and -NP). We ran a mixed-logit model for each +NP and -NP subset of the data with Object Animacy as predictor and the same co-variate and mixed-effects structure as in the final main model. In the case of + NP questions ${ }^{9}$, we find that presence of a +Animate object significantly affects comprehension $(\beta=-0.72, S E=0.11, z=-6.17, p<.001)$. No such effect of Object Animacy appears with $-\mathrm{NP}$ questions ${ }^{10}(\beta=-0.21, S E=0.18, z=-1.12, p=.26)$. When looking at the effect of Lexical Restriction on the two levels of Object Animacy (+Animate and -Animate), using the same procedure as outline above for the +NP and -NP conditions, we see that comprehension accuracy significantly improves with -NP questions both in the case of questions introduced by a +Animate $\operatorname{object11}^{11}(\beta=1.96, S E=0.30, z=6.60, p<.001)$ and in the case of questions introduced by a -Animate $\operatorname{object}^{12}(\beta=1.21, S E=0.32, z=3.78, p<.001)$. These pairwise comparisons indicate that the interaction between Lexical Restriction and Object Animacy in the main analysis was caused by Object Animacy having an effect in +NP, but not in -NP questions.

We now turn to the results of the mixed logit model for relative clauses. Like in the case of wh-questions, we started the analysis with a model that included all fixed effects, covariates and interactions between them. The final model was again selected by removing factors one at a time until the fit of the smaller model was not significantly worse than the fit of the larger model. This showed that the interactions with Forward digit-span $\left(\chi^{2}(1)=1.56, p=.21\right)$ and Backward-digit span $\left(\chi^{2}(1)=2.84, p=.10\right)$ were not significant. The interaction between Lexical Restriction and Object Animacy was significant $\left(\chi^{2}(1)=17.64\right.$,

\footnotetext{
${ }^{9}$ Number of observations $=488$, log-likelihood $=-280.2$, Participant SD $=0.68$.

10 Number of observations $=244$, log-likelihood $=-96.9$, Participant SD $=0.54$.

11 Number of observations $=366$, log-likelihood $=-212.2$, Participant SD $=0.52$.

12 Number of observations $=366$, log-likelihood $=-169.8$, Participant SD $=0.50$.
} 
$p<.001)$, as was the interaction with Age $\left(\chi^{2}(1)=7.14, p<.01\right)$. Tables 5 and 6 summarize the fixed effects and random effects of the final full model.

Table 5

Fixed effect estimates for mixed logit model of correct answers for RCs (ResponseAccuracy LexicalRestriction * ObjectAnimacy * Age + (ForwardDspan + BackwardDspan $)+(1 \mid$ Participant); $\mathrm{N}=732$, AIC = 788.79, $\mathrm{BIC}=839.34$, log-likelihood $=-383.40$ )

\begin{tabular}{lllll}
\hline Fixed effect & Coefficient & $S E$ & Wald $Z$ & $p$ \\
\hline (Intercept) & -0.88 & 0.55 & -1.58 & $>.1$ \\
Lexical Restriction = -NP - +NP & 0.15 & 0.23 & 2.75 & $>.05$ \\
Object Animacy = + Animate - -Animate & -1.73 & 0.24 & -7.27 & $<.001^{* * *}$ \\
Age & 0.03 & 0.007 & 4.08 & $<.001^{* * *}$ \\
Forward D-span & 0.41 & 0.12 & 3.46 & $<.001^{* * *}$ \\
Backward D-span & -0.05 & 0.13 & -0.42 & $>.6$ \\
Interaction = Lexical Restriction \& Object Animacy & -1.71 & 0.47 & -3.62 & $<.001^{* * *}$ \\
Interaction = Lexical Restriction \& Age & 0.006 & 0.009 & 0.62 & $>.5$ \\
Interaction = Object Animacy \& Age & 0.0006 & 0.009 & 0.06 & $>.9$ \\
Interaction = Lexical Restriction \& Object Animacy \& Age & 0.011 & 0.02 & 0.63 & $>.5$ \\
\hline
\end{tabular}

Table 6

Summary of random effects in the mixed logit model for RCs

\begin{tabular}{lll}
\hline Random effect & $\mathrm{s}^{2}$ & SD \\
\hline Participant Intercept & 0.44 & 0.67 \\
\hline
\end{tabular}

-NP object RCs yield slightly higher accuracy scores as compared to +NP object RCs, but the effect of the absence of a lexical restriction on the head of the relative clause is not significant, contrary to the results obtained for wh-questions (see Table 3 for reference). The [ \pm Animate] nature of the object also affects comprehension, as children comprehend object RCs headed by a +Animate DP less accurately than object RCs headed by a -Animate DP. There was also a significant interaction between Lexical Restriction and Object Animacy (Figure 6), as revealed by the results of the mixed logit model: this shows that Object Animacy determines a bigger difference in performance on -NP trials than on +NP trials. 


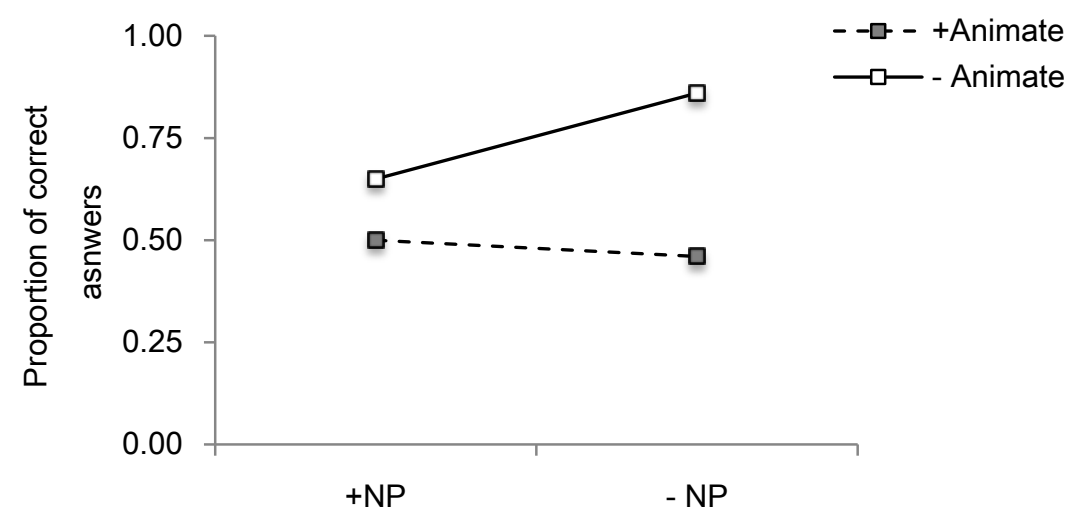

Figure 6. Overall proportion of correct answers for RCs as a function of lexical restriction (+/-NP) and object animacy (+/-Animate) for all age groups

As for the effects of the covariates, we observe again, like in the case of wh-questions, a significant effect of Age $(\beta=0.03, S E=0.007, z=4.08, p=<0.001)$ and of Forward digit span $(\beta=0.41, S E=0.12$, $z=3.46, p=<0.001)$ : responses accuracy is higher in older children and children with higher forward digit-span scores. No significant effect of Backward digit span $(\beta=-0.05, S E=0.13, z=-0.42, p=$ $<0.001$ ) was observed.

In order to see what drives the difference in the interaction effect, we performed preplanned pairwise comparisons on different subsets of the data as in the case of wh-questions. First we ran mixed logit models for both +NP and -NP relative clauses with Object Animacy as predictor and the same co-variate and mixed-effects structure as in the final main model. Here again we find a significant effect of Object Animacy on +NP RCs ${ }^{13}$, showing that comprehension accuracy is lower for +Animate +NP object RCs than for -Animate +NP object RCs $(\beta=-0.42, S E=0.10, z=-3.90, p<.001)$. In contrast with whquestions, the mixed-model for $-\mathrm{NP}$ relative clauses $^{14}$ reveals that Object Animacy also had a significant effect on the comprehension of -NP RCs, so RCs headed by celui/celle or ce: children are much less accurate with +Animate -NP object $\mathrm{RCs}(\beta=-1.32, S E=0.23, z=-5.60, p<.001)$ than with -Animate NP object RCs. In addition, we also analyzed whether Lexical Restriction affects +Animate and Animate conditions to the same extent, by fitting the +Animate and -Animate data subsets to two mixedlogit models this time with Lexical Restriction as predictor. For +Animate object RCs ${ }^{15}$ the presence of a -NP head noun does not modulate comprehension $(\beta=-0.20, S E=0.26, z=-0.77, p=.44)$, while it significantly improves comprehension for -Animate object $\operatorname{RCs}^{16}(\beta=1.57, S E=0.35, z=4.52, p<$

\footnotetext{
13 Number of observations $=488$, log-likelihood $=-279.6$, Participant SD $=0.58$

14 Number of observations $=244$, log-likelihood $=-106.8$, Participant SD $=0.60$

15 Number of observations $=366$, log-likelihood $=-212.7$, Participant SD $=0.55$

16 Number of observations $=366$, log-likelihood $=-173.7$, Participant SD $=0.82$
} 
.001). These pairwise comparisons show that the interaction in the case of RCs is driven by the difference in the effect of Lexical Restriction on +Animate and -Animate object RCs.

\section{Discussion}

To recall, the present study seeks to refine our understanding of RM effects in child grammar through an analysis of the role that certain crucial morphosyntactic features play in triggering intervention in A'dependencies. We pursue this empirically by investigating the comprehension of object wh-questions and RCs in French-speaking children between 5 and 11 years old. Within each construction, we focus on the moved object by manipulating two sets of features ([ $\pm N P]$; $[ \pm$ Animate]), while the intervener (the embedded subject) is invariably +NP +Animate.

The experimental findings demonstrate that the presence of +NP+Animate features on both the intervener and the A'-moved object make it difficult for children to relate the gap to its antecedent. These findings lend support to the grammatical intervention hypothesis (Friedmann et al. 2009) which claims that computing object $A^{\prime}$-dependencies is problematic for children when an inclusion relation holds between the sets of features present on the embedded subject and the target (i.e. the antecedent of the gap).

Let us consider first our results in the case of questions (figure 2). There is a clear distinction in all age groups between the bare and the lexically restricted conditions. The distinction manifests itself most straightforwardly in the 5-year-old group and shows that questions with a bare wh (whether animate or not, as in (19)), are better understood than questions with a lexically restricted wh (illustrated in (20)):

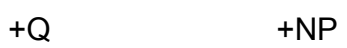

(19) a. Qui est-ce que la fille embrasse?

who ESK the girl kisses?

$+\mathrm{Q} \quad+\mathrm{NP}$

b. Qu' est-ce que la fille frappe?

what ESK the girl hits

$+\mathrm{Q}+\mathrm{NP} \quad+\mathrm{NP}$

(20) a. Quelle dame est-ce que la fille embrasse?

which lady ESK the girl kisses

$+\mathrm{Q}+\mathrm{NP} \quad+\mathrm{NP}$

b. Quelle balle est-ce que la fille frappe?

which ball ESK the girl hits 
This is directly in line with the prediction of a RM-based approach to the acquisition of these constructions: configurations like (20) in which the features on the moved object include the [+NP] feature on the intervening subject are harder for young children to deal with than configurations like (19) where the featural sets on the two elements are disjoint.

A contrast between +NP and -NP wh-questions emerges in a different form in the 7-, 9-, and 11-year-old groups. The lexically restricted case is sensitive to animacy, with a significant improvement of comprehension with animacy mismatch (first and second bar in figure 2), while the bare wh case is not significantly sensitive to animacy distinctions (third and fourth bar of figure 2). How can this be interpreted?

Clearly, older children ( 7 - 11yo) can interpret animacy as a relevant feature and draw upon its presence to distinguish the set of features present on the intervener from those of the $A^{\prime}$-object. The mismatch in animacy thus creates an intersection relation between the features entering the computation (Belletti et al., 2012). According to Belletti et al. (2012), a feature can have a facilitating effect inasmuch as it acts as a trigger for movement, a core case being movement to subject position triggered by the Phi feature set expressed in the verbal morphology. Animacy effects of the kind emerging from our data may suggest that features morphologically unrealized on the clausal inflectional head can nevertheless impact the computation of intervention. This is entirely expected under the core theory of RM (Rizzi 1990, 2004), primarily designed to capture violations of weak islands in adult grammars. The fundamental case is the deviant extraction from a wh-island, in which the feature involved is $Q$, or other A'-features, features typically not expressed in the verbal morphology. Clearly, the crucial property which makes a feature visible for the computation of RM is its capacity to trigger movement, not the fact that it is morphologically expressed on $\mathrm{V}$ (being morphologically expressed on $\mathrm{V}$ may be a sufficient criterion for being taken into account by RM, as in the discussion of the gender feature in Hebrew in Belletti et al. 2012, clearly not a necessary one).

Going back to the observed animacy effect, can one maintain in this connection that the only features taken into account in the calculation of locality are those which have an active role in triggering movement? Bianchi (2006) argues, based on the so-called Person-Case constraint in Romance languages (which determines ordering restrictions in clitic sequences), that even non-animacy based languages ${ }^{17}$ like Italian encode an animacy hierarchy in a system of Person heads against which all pronominal arguments must license their person feature. Therefore it is plausible to assume that animacy (or perhaps, animate person) plays a crucial role in triggering movement also in our languages,

\footnotetext{
${ }^{17}$ Research in comparative linguistics has shown on independent grounds that variations in animacy are associated with variations in syntax, such as differential case-marking and voice selection in certain languages (Aissen, 2003, Comrie, 1989).
} 
and perhaps universally, even though its effects are easier to detect in some languages than in others. If this is so, the relevance of animacy for the calculation of RM would be expected.

A less selective perspective to the identification of features favoring the resolution of $A^{\prime}$-dependencies is adopted by the so-called "similarity-based" approach to interference (Gordon et al. 2004, Lewis et al. 2006, Van Dyke \& McEIree 2006, 2011), according to which any featural dissimilarity between the target and the intervener is of help (i.e. dissimilarity not just in morphosyntactically relevant features, but also in purely semantic, or purely phonological features; see Belletti et al. (2012) for discussion). In that approach, animacy impacts performance because it acts as a semantic cue and therefore facilitates theta-role assignment, quite irrespective of the structural realization and role of the feature.

Our results may bear on the controversy between structurally selective and unselective approaches here. If the child paid attention to such cues merely to overcome a memory problem for the proper assignment of theta roles, as in the unselective approaches, we would expect similar performance regardless of the structural realization of the animacy cue: the mere semantic mismatch in animacy would suffice to accurately parse the structure and arrive at the correct assignment of theta roles. Although this analysis may be intuitively appealing, it cannot account for all of our results. All featural differences do not seem to be on a par as global interpretive properties of the two nominal expressions involved.

Crucially, a mismatch in animacy does not significantly improve comprehension at any age in -NP questions with qui (who) and que (what). From the viewpoint of an unselective approach, this is unexpected, since qui and que semantically contrast in animacy as much as quelle fille (which girl) and quelle balle (which ball) do. Therefore, the contrastive feature would be expected to yield a similar result in facilitating comprehension, contrary to fact. On the other hand, if one pays attention to the locus where the animacy feature is formally expressed, a clear difference emerges. Animacy is directly expressed by the wh-determiner in qui / que, while it is expressed by the lexical restriction in quelle fille / quelle balle, much as in the intervening subject (la fille) in examples (19) and (20) above. This suggests that the system compares strictly parallel features as far as their structural encoding is concerned. One possible implementation would involve a featural hierarchy (Bianchi 2006, Carminati 2005, Harley and Ritter 2002) of the kind illustrated in (21), which is referred to when featural structures are compared:

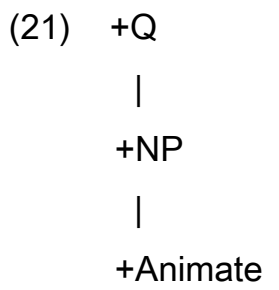


So, when quelle balle and la fille are compared in the following,

$+\mathrm{Q}+\mathrm{NP}-\mathrm{An} \quad+\mathrm{NP}+\mathrm{An}$

Quelle balle est-ce que la fille frappe?

they differ in the [+Q] feature of quelle balle, but they are both classified as [+NP]. At this point the comparison goes on through the hierarchy in (21) and the -Animate feature in quelle balle is compared with the +Animate feature in la fille (+An); this yields an intersection situation (quelle balle is $[+\mathrm{Q}+\mathrm{NP}$ Animate], while la fille is [+NP +Animate]). As expected under Belletti et al.'s interpretation of the different set theoretic relations between the featural specifications of the target and the intervener (summarized in the introduction), the child understands better the intersection relation in (22) than the inclusion relation of the following:

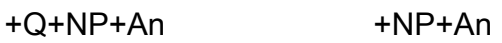

Quelle dame est-ce que la fille embrasse?

Let us now consider the cases of a bare wh-element, exemplified in (19a) and (19b) above and repeated here as (24) and (25) for ease of reference:

$+\mathrm{Q}-\mathrm{NP}+\mathrm{An} \quad+\mathrm{NP}+\mathrm{An}$

Qui est-ce que la fille embrasse?

$+\mathrm{Q}-\mathrm{NP}-\mathrm{An} \quad+\mathrm{NP}+\mathrm{An}$

(25) Qu' est-ce que la fille frappe?

Assuming the hierarchy in (21) as a guideline for the comparison, here the wh word is [+Q $-N P]$, while the intervening subject is $[-Q+N P]$. The $+/-$ animacy feature is not uniformly expressed in the target and the intervener: in one case, it is associated with a -NP element and, in the other, with a +NP one. As such, the animacy feature is not taken into account in (24) and (25) under the assumption that only features structurally encoded in a parallel fashion are compared. More specifically, the animacy feature is taken into consideration when, for example, both the target and the intervener bear a +NP feature, like in (22) or (23) above. In examples like (24 and (25), we end up with a disjunction configuration ([+Q -NP] vs. $[+N P])$, the easiest configuration to deal with, which is in fact quite well understood by children in all age groups regardless of the animacy specification (bars 3 and 4 in figure 2). The selective effect of animacy in age groups $7 y, 9 y$ and $11 y$ supports a selective approach to the identification of the features relevant for locality, one in which it is precisely the structural role and the locus of encoding of a feature that matters and not just its semantic import.

Back to the animacy effect with lexically restricted [+NP] wh-questions (the first and second bars in figure 2), we have observed that, while the effect is present in the older age groups, it does not surface 
in the 5-year-old group. Indeed 5-year-old children do not perform better with A'-dependencies headed by a +NP, -Animate object, showing that they cannot exploit the mismatch in animacy in these contexts. We observe that Animacy, being a subfeature of $+\mathrm{NP}$, is deeply embedded in the hierarchical organization (21). Therefore, we may speculate that the processing cost associated with the computation of this feature appears to be too high to pay for younger children and thus leads to comprehension difficulties ${ }^{18}$. The results suggest that children's limited processing resources make it difficult to activate, select, maintain, and manipulate the full array of morphosyntactic features required to distinguish the intervening subject from the moved object (Garraffa \& Grillo 2008, Adani 2008, Grillo 2008). If the selection of each morphosyntactic feature comes with a processing cost, it follows that features will be more or less readily accessible, depending on the position that they occupy in an independently motivated hierarchy of morphosyntactic features (Grillo 2008). If the [ \pm Animate] feature is not computed here, the representation is one of inclusion, a difficult one to process for the young child. A (nonexclusive) alternative is that it may simply be the case that the intersection configuration may be a difficult configuration to compute, possibly not accessible to the youngest group (see Belletti et al. 2012 for discussion). This hints at the idea that, since both the inclusion and intersection relations require a comparison between sets of features, these operations are only taken into account at a later time and become relevant only at a certain age. In this perspective, disjunction, intersection, inclusion and identity can be looked at as involving different degrees of distinctness between target and intervener (maximal with disjunction, minimal with identity, and with intersection and inclusion expressing two different intermediate degrees). It is thus natural to expect that the highest degree of distinctness, disjunction, will be properly computed earlier than the immediately lower degree, intersection, which will be in turn properly computed earlier than the next degree, inclusion (whereas identity remains strictly excluded in both child and adult systems).

Turning now to the case of object relatives (figure 3), we observe that the pattern is essentially the same as for object questions in three out of four cases, whereas it clearly differs in the celui/celle case (third

\footnotetext{
${ }^{18}$ Another way to investigate the effect of animacy would be to test the comprehension of object wh-questions/ RCs with an animate object and an inanimate embedded subject, along the lines of Adani (2012). Crucially, Adani (2012) did not find an effect of this mismatch in animacy on the comprehension of object relative clauses in 4- to 5-year-old German-speaking children. This could be interpreted as evidence against the extension of the feature-based approach to the animacy specification. It is important to note, though, that our results also show that the younger children in our experiment (i.e. the 5-year-olds) could not exploit the mismatch in animacy we tested, showing that they have difficulties computing the whole array of morphosyntactic features required to distinguish the intervening subject from the moved object. However, several interesting questions remain: Does a mismatch in animacy similar to the one tested in Adani (2012) have an effect in older children as well? Does it surface even in younger children with finer-grained experimental techniques (i.e. eye-tracking)? We leave these to future research.
} 
bar in figure 3). Lexically restricted +NP relatives exemplified in (26) show an animacy effect favoring the mismatching structure in the 7 and 9-year-old groups, which is absent from the 5-year-old group. As for the 11-year-olds, there is a clear difference in performance between +NP +Animate and +NP -Animate RCs, although this difference does not reach significance.

$+\mathrm{R}+\mathrm{NP}+\mathrm{An} \quad+\mathrm{NP}+\mathrm{An}$

(26) a. Montre-moi la dame que la fille embrasse.

show-me the lady that the girl kisses

$+\mathrm{R}+\mathrm{NP}-\mathrm{An} \quad+\mathrm{NP}+\mathrm{An}$

b. Montre-moi la balle que la fille frappe.

show-me the ball that the girl hits

Much like in the case of wh-questions, the low scores of the 5-year-old children with +NP RCs, as well as their similar performance on both +Animate and -Animate RCs illustrated in (26) can be taken as evidence that younger children have difficulties exploiting the mismatch in animacy in contexts of an intervention configuration. On the other hand, the lack of an effect of animacy in the case of the 11 yearolds can be attributed to the fact that they comprehens +NP +Animate trials very well. In turn, this improved performance considerably reduces the difference with the +NP -Animate trials.

As for the case of relatives headed by a non lexically restricted -NP element, the inanimate ce case (montre-moi ce que la fille frappe) is the easiest structure for all groups, much as the que case in questions (qu'est-ce que la fille frappe?). In contrast with questions introduced by qui, the animate celuilcelle case (montre-moi celle que la fille embrasse) is significantly more difficult than the inanimate ce case for all groups, and is indeed the most difficult case of all for the younger 5 and 7-year-old children. Why do we find such a sharp difference only between celui/celle and ce and not between qui and que? If celui/celle vs ce were the straightforward relative counterpart of the questions with bare wh qui vs que, we would expect no significant difference between bars 3 and 4 of figure 3, contrary to fact. Clearly, celui/celle differ from $c e$ in several respects: (i) they permit an animate interpretation, (ii) they have a different internal structure (while ce may be analyzed as a bare D, ce-/ui / c-elle clearly have a more complex structure with the determiner ce plus a pronominal form (/ui-elle) which may plausibly be analyzed as a pro-NP form ${ }^{19}$ ), and (iii) they are anaphoric expressions due to the pronominal part /ui/elle which assigns an anaphoric interpretation to the whole constituent.

\footnotetext{
19 This is only a first approximation. If we take into account a richer cartography of the DP, lui-elle may well pronominalize a higher functional layer of the DP, possibly parallel to the layer pronominalized by English one in DPs like the one which.... The crucial point is that the celui-celle structure involves an overt complement of D, much as the DP structure of la fille, etc. This is the formal parallelism that the discussion in the text capitalizes on.
} 
If one focuses on the formal structure of target and intervener, an immediate observation is that the relative head has the same D+NP form as the intervening subject (la fille):

\section{(27) Montre-moi celle show-me this/that+her that the girl kisses} $+\mathrm{NP}+\mathrm{An}$

If this way of looking at things is correct, what counts in the calculation of the relevant morphosyntactic configuration may not be the presence of an actual $\mathrm{N}$ (noun) from the contentive lexicon heading the lexical restriction, but the formal presence of a D+NP structure (or the complex structure alluded to in the preceding footnote). Under this interpretation, (27) would thus instantiate an inclusion configuration.

The inanimate version with ce would have a head with no restriction (either from a lexical or a pronominal nominal element):

\section{(28) Montre-moi ce que la fille frappe show-me what that the girl hits}

Therefore, the difficulty with ce+lui / c+elle could suggest that the crucial divide is not between a DP with a restriction taken from the contentive lexicon and a DP not so restricted, but between a DP analyzable as D+NP and one analyzable as a bare D. This would give rise to a disjunction configuration in (28), correctly expected to be the most accessible case to the child system. The anomaly of the celuilcelle case may thus receive an analysis which underscores the importance of the structural configuration of the target and the antecedent in the computation of locality.

Another observation concerning RCs introduced by celui/celle is that they yield chance-level performance in the 5 and 7 -year-old children. This leads to a sharp difference in comprehension accuracy between celui/celle and ce, but also to an asymmetry between celui/celle and RCs headed by a full lexical noun. These findings suggest that, as far as these two age groups are concerned, we are dealing with a compounding of effects: on the one hand, the formal structure of celui/celle creates an intervention configuration with the embedded subject; on the other hand, there is an added complexity with these structures possibly associated with a difficulty in accessing the discourse referent of these expressions. We could therefore suppose that, once children overcome this intrinsic problem with celui/celle related to the assignment of a referent, their comprehension scores for celui/celle headed RCs will pattern with those for lexically-restricted RCs and that the difference in performance with $c e$ $\mathrm{RCs}$ is greatly reduced, like we see for the 9 and 11 year-olds.

The above analysis of celui/celle and ce also allows us to explain the opposite pattern of the interaction 
Lexical restriction by Object Animacy that we found in wh-questions and in RCs. While in wh-questions only performance in +NP trials is affected the Animacy match/mismatch, in RCs performance in both $+\mathrm{NP}$ and -NP trials is affected by the mismatch in Animacy, which also triggers a bigger difference in the case of -NP trials (so celui/celle and ce). In light of our analysis of celui/celle as D+NP and of ce as -NP, we see that the improved performance with ce RCs, as compared to celui/celle RCs, is driven by the fact that the ce structures represent a true case of featural disjunction between the moved object and the intervening subject, while celui/celle RCs create an intervention configuration in terms of +NP match. The difference between the +Animate celui/celle RCs and the -Animate ce RCs therefore stems not only from the difference in object animacy, but also from the difference in the +/- NP specification of the relative head.

When it comes to measuring the cost associated with the processing of object $A^{\prime}$-dependencies and the computing of the sets of features required to distinguish among the potential antecedents of the object gap, the main effect of forward digit-span we found suggests that, across all age groups and across all tested conditions, higher scores on the digit-forward test determined higher accuracy scores. The results reveal that the forward span is predictive of children's performance with both wh-questions and relative clauses, indicating that the phonological loop plays a role in A'-processing. This is in line with previous findings that have investigated the relationship between forward digit-span performance and processing of relative clauses. For example, Booth et al. (2000) found that forward digit span predicted the online processing of subject and object center-embedded relative clauses in 8- to 12-year-old English children. Arosio et al. (2011) also reported a link between 9-year-old Italian children's forward digit-span scores and their offline comprehension of object relative clauses. The backward digit span, a task used as a measure of central executive functioning, does not show a relation with syntactic performance. This might be likely due to the overall low scores at this task, especially among the younger children. Our findings corroborate the results of Boyle et al. (2013) who fail to find a relation between backward digitspan performance and comprehension of subject and object relative clauses in 4- to 6-year-old Englishspeaking children. In contrast, Felser et al. (2003) reported that 6- to 7-year-old children's listening span, a measure that also seems be dependent on central executive functioning, predicted their online ambiguity resolution with respect to relative clause attachment. This would suggest that in order to establish a link between central executive functioning and performance with A'-dependencies, care must be taken so as to identify the right sort of memory task.

Although the exact contribution of the two components of WM (the phonological loop and the central executive) on the interpretation of $A^{\prime}$-dependencies is not clear, the impact of forward digit span scores on response accuracy suggests that limitations in memory resources affect the processing of A'dependencies. Therefore, the comprehension differences between children seem to be related to the different resources available for computation. 


\section{Conclusion}

The present study was concerned with the features that impact the processing of object A'dependencies, the conditions under which they do so, as well as the relation between working memory abilities and the computational complexity of A'-structures. Our results on object questions and on object relatives headed by $c e$ clearly point to the critical role of the lexical restriction (the +NP feature) in modulating comprehension. This is expected under the RM approach: when the A'-moved element is not lexically restricted, the A'-dependency is more easily computed by the child across a +NP subject, a disjunction configuration in the adopted system. Our experimental findings also show that minimality effects still appear in object RCs headed by celui/celle (abstracting away from other problems which may affect this construction) thus suggesting that the notion of lexical NP feature needs to be further refined, as it seems to be too coarse to capture the difficulties that French-speaking children have with these constructions. Therefore, intervention should be defined so as to accommodate the formal presence of a $\mathrm{D}+\mathrm{NP}$ structure (or the more complex structure alluded to in fn 19) and not just the presence of a noun from the contentive lexicon heading a lexical restriction. The general pattern that we obtain across age groups and across A'-dependencies shows that children perform best with configurations containing a disjunction in the NP feature on the target and the intervener. The most problematic configurations for children are those in which the features on the intervener (NP, Animacy) are included in the set of features present on the target. When an inanimate, lexically restricted object is moved across an animate subject, the resulting intersection configuration improves comprehension, but the effect is only observed in the 7, 9, 11 year old groups, which suggests that the intersection relation is not computed initially. Moreover, the mismatch in Animacy does not significantly improve comprehension in bare questions with who and what in any age group. We interpret this as supporting the view that the animacy effect depends on the locus where the feature is expressed (whether it is associated or not with a +NP feature), in line with the expectations of a restrictive, structure-sensitive approach to intervention in early systems. Our results also illustrate the connection between memory resources and comprehension of A'dependencies: increased working memory abilities, as measured by the digit-forward test, facilitate comprehension of object wh-questions and object relative clauses.

\section{Appendix A. Materials for Wh-questions (by condition)}

\begin{tabular}{lc}
\hline Sentences & Condition \\
\hline quelle fille est-ce que la dame maquille? & +NP +Animate \\
'which girl is the lady putting make up on?' & \\
quelle princesse est-ce que la grenouille embrasse? & $+\mathrm{NP}+$ Animate \\
'which princess is the frog kissing?' & $+\mathrm{NP}+$ Animate
\end{tabular}


'which rabbit is the cat punching?'

quel canard est-ce que le lapin caresse?

$+\mathrm{NP}+$ Animate

'which duck is the rabbit petting?'

quelle balançoire est-ce que la fille frappe?

+ NP -Animate

'which swing is the girl hitting?'

quelle balle est-ce que la poule suit?

+NP -Animate

'which ball is the hen following?'

quel tuyau est-ce que l'éléphant arrose?

+NP -Animate

'which hose is the elephant splasing?'

quel ballon est-ce que le garçon tape?

+NP -Animate

'which ball is the boy hitting?'

qui est-ce que la giraffe lèche? (la vache)

$-\mathrm{NP}+$ Animate

'who is the giraffe licking?' (the cow)

qui est-ce que le pompier mouille? (le garçon)

$-\mathrm{NP}+$ Animate

'who is the firefighter splashing?' (the boy)

qu'est-ce que la fille frappe? (la porte)

-NP -Animate

'what is the girl hitting?' (the door)

qu'est-ce que l'enfant salit? (le camion)

-NP -Animate

'what is the boy dirtying?' (the truck)

Appendix B. Materials for relative clauses (by condition). "Show me ..." was used as lead-in for all the sentences.

\begin{tabular}{|c|c|}
\hline Sentences & Condition \\
\hline la fille que la grand-mère sèche. & $+\mathrm{NP}+$ Animate \\
\hline \multicolumn{2}{|l|}{ 'the girl that the lady is drying.' } \\
\hline la dame que la petite-fille embrasse. & $+\mathrm{NP}+$ Animate \\
\hline \multicolumn{2}{|l|}{ 'the lady that the girl is kissing.' } \\
\hline le chameau que le zèbre suit. & $+\mathrm{NP}+$ Animate \\
\hline \multicolumn{2}{|l|}{ 'the camel that the zebra is following.' } \\
\hline le cochon que l'enfant salit. & $+\mathrm{NP}+$ Animate \\
\hline \multicolumn{2}{|l|}{ 'the pig that the boy is dirtying.' } \\
\hline la pelote que la chatte suit. & $+\mathrm{NP}$-Animate \\
\hline
\end{tabular}


la casserole que la dame salit.

$+\mathrm{NP}$-Animate

'the pot that the lady is dirtying.'

le tuyau que le garçon arrose.

$+\mathrm{NP}$-Animate

'the hose that the boy is splasing?'

le vélo que le chien pousse.

+NP -Animate

'the bike that the dog is pushing.'

celle que la reine photographie. (la fille)

-NP +Animate

'the one that the queen is photographing.' (the girl)

celui que le cheval suit. (le bébé)

-NP +Animate

'the one that the horsey is following.' (the baby)

ce que la fille touche (la boule de neige)

-NP -Animate

'what the girl is touching?' (the snowball)

ce que l'éléphant écrase. (l'arbre)

-NP -Animate

'what the elephant is crushing?' (the tree trunk)

\section{References:}

Adani, F. 2008 Re-thinking the acquisition of Relative Clauses in Italian: a new comprehension study with Italian children. Proceedings of the 27 West Coast Conference in Formal Linguistics, University of California, Los Angeles.

Adani, F., van der Lely, H.K.J., Forgiarini, M., Guasti, M.T. 2010. Grammatical feature dissimilarities make RCs easier: a comprehension study with Italian children. Lingua 120, 2148-2166. doi.org/10.1016/j.lingua.2010.03.018.

Adani, F. 2011. Rethinking the acquisition of RCs in Italian: towards a grammatically based account. Journal of Child Language 38, 141-165. doi.org/10.1017/S0305000909990250.

Adani, F. 2012. Some notes on the acquisition of Relative Clauses: New Data and Open Questions, In Bianchi, V., \& Chesi, C. (eds.) ENJOY LINGUISTICS! Papers offered to Luigi Rizzi on the occasion of his 60th birthday, Centro Interdipartimentale di Studi Cognitivi sul Linguaggio, University of Siena.

Aissen, J. 2003. Differential object marking: iconicity vs. economy. Natural Language and Linguistic Theory 21, 435- 483. doi: 10.1023/A:1024109008573.

Arnon, I. 2005. RC acquisition in Hebrew: Towards a processing-oriented account. In Brugos, A., ClarkCotton, M. R. \& Ha, S. (eds.), Proceedings of the 29th Boston University Conference on Language Development, Cascadilla Press, Somerville: MA. 
Arnon, I. 2010. Rethinking child difficulty: the effect of NP type on children's processing of RCs in Hebrew. Journal of Child Language 37, 27-57. doi.org/10.1017/S030500090900943X.

Arosio, F., Guasti, M. T., Stucchi, N. 2011. Disambiguating information and memory resources in children's processing of Italian RCs. Journal of Psycholinguistic Research, 40, 137-154. doi.org/10.1007/s10936-010-9160-0.

Atkinson, M. 1996. Now, hang on a minute: some reflections on emerging orthodoxies. In Clahsen, $\mathrm{H}$. (ed.) Generative Perspectives on Language Acquisition, John Benjamins, Amsterdam, pp. 451-487.

Avrutin, S. 2000. Comprehension of Wh-questions by children and Broca's aphasics. In Grodzinsky et al (eds.), Language and the brain: Representation and processing, Academic Press, San Diego, CA, pp 295-312.

Baayen, R. H., Davidson, D. J., Bates, D. M. 2008. Mixed-effects modelling with crossed random effects for subjects and items. Journal of Memory and Language 59, 390-412. doi:10.1016/j.jml.2007.12.005.

Baddeley, A. 2000. The episodic buffer: A new component of working memory? Trends in Cognitive Sciences 4, 417-423. doi:10.1016/S1364-6613(00)01538-2.

Baddeley, A. 2007. Working memory, thought, and action, Oxford University Press New York.

Bates D., Maechler, M., Bolker, B., Walker, S. 2014. "Ime4: Linear mixed-effects models using Eigen and S4", R package version 1.1-7, http://CRAN.R-project.org/package=Ime4.

Baudiffier, V., Caplan, D., Gaonac'h, D., Chesnet, D. 2011. The effect of noun animacy on the processing of unambiguous sentences: Evidence from French RCs, The Quarterly Journal of Experimental Psychology 64(10), 1896-1905. doi:10.1080/17470218.2011.608851.

Becker, M. 2009. The Role of NP Animacy and Expletives in Verb Learning, Language Acquisition 16, 283-296. doi: 10.1080/10489220903178997.

Belletti, A., Friedmann, N., Brunato, D., Rizzi, L. 2012. Does gender make a difference? Comparing the effect of gender on children's comprehension of RCs in Hebrew and Italian. Lingua 122, 1053-1069. doi:10.1016/j.lingua.2012.02.007.

Belletti, A. and Chesi, C. 2011. Relative Clauses from the input: syntactic considerations on a corpusbased analysis of italian. Studies in Linguistics (CISCL Working Papers) Vol.4.

Bianchi, V. 2006. On the syntax of personal arguments. Lingua 116, 2023-2067. doi.org/10.1016/j.lingua.2005.05.002.

Booth, J. R., MacWhinney, B., Haraskai, Y. 2000. Developmental differences in visual and auditory processing of complex sentences. Child Development 71, 981-1003. PMID: 11016560.

Boyle, W., Lindell, A. K., Kidd, E. 2013. Investigating the Role of Verbal Working Memory in Young 
Children's Sentence Comprehension. Language Learning 63:2, 211-242. doi: 10.1111/lang.12003.

Brandt, S., Kidd, E., Lieven, E., Tomasello, M. 2009. The discourse bases of relativisation: An investigation of young German and English-speaking children's comprehension of RCs. Cognitive Linguistics 20:3, 539-570. doi: 10.1515/COGL.2009.024

Carminati, M.N., 2005. Processing reflexes of the feature hierarchy (person $>$ number $>$ gender) and implications for the linguistic theory. Lingua 115, 259- 285. doi:10.1016/j.lingua.2003.10.006

Chomsky, N. 1995. The Minimalist Program. MIT Press, Cambridge, MA.

Comrie, B. 1989. Language Universals and Linguistic Typology. University of Chicago Press, Chicago.

Corrêa, L. 1995. An alternative assessment of children's comprehension of RCs. Journal of Psycholinguistic Research 24, 183-203. doi: 10.1007/BF02145355.

Costa, J., Lobo, M., Silva, C. 2011. Subject-object asymmetries in the acquisition of Portuguese relative clauses: Adults vs. children. Lingua 121, 1083-1100. doi:10.1016/j.lingua.2011.02.001.

de Villiers, J.G., de Villiers, P.A., Hoban, E. 1994. The central problem of functional categories in the English syntax of oral deaf children. In: Tager-Flusberg, H. (ed.), Constraints on Language Acquisition: Studies of Atypical Children. Erlbaum, Hillsdale, NJ, pp. 9-47.

Felser, C., Marinis, T., Clahsen, H. 2003. Children's processing of ambiguous sentences: A study of RC attachment. Language Acquisition 11, 127-163. doi:10.1207/s15327817la1103_1.

Friedmann, N., and Novogrodsky, R. 2004. The acquisition of RC comprehension in Hebrew: A study of SLI and normal development. Journal of Child Language 31, 661-681. doi: 10.1017/S0305000904006269.

Friedmann, N., Belletti, A., Rizzi, L. 2009. Relativized Relatives: types of intervention in the acquisition of A'-dependencies. Lingua 119, 67-88. doi:10.1016/j.lingua.2008.09.002.

Garraffa, M., Grillo, N. 2008. Canonicity effects as grammatical phenomena. Journal of Neurolinguistics 21, 177-197. doi:10.1016/j.jneuroling.2007.09.001.

Gibson, E. 1998. Linguistic complexity: Locality of syntactic dependencies. Cognition 68, 1-76. doi: S0010-0277(98)00034-1

Goodluck, H., and Tavakolian, S. 1982. Competence and processing in children's grammar of RCs. Cognition 11, 1-27. doi.org/10.1016/0010-0277(82)90002-6.

Gordon, P.C., Hendrick, R., Johnson, M. 2004. Effects of noun phrase type on sentence complexity. Journal of Memory and Language 51 (2004) 97-114. doi:10.1016/j.jml.2004.02.003.

Grillo, N. 2008. Generalized minimality: syntactic underspecification in Broca's aphasia. Doctoral 
Dissertation. Distributed by LOT, University of Utrecht, The Netherlands.

Grodner, D.J., and Gibson, E. 2005. Consequences of the Serial Nature of Linguistic Input for Sentential Complexity. Cognitive Science 29, 261-291. doi: 10.1207/s15516709cog0000_7.

Gross, M. 1968. Grammaire transformationnelle du français. Syntaxe du verbe, Paris: Larousse.

Harley, H., and Ritter, E., 2002. Person and number in pronouns: motivating a feature-geometric analysis. Language 78:3, 482-526. DOI: 10.1353/lan.2002.0158

Hyams, N. 1996. The underspecification of functional categories in early grammar. In Clahsen, H. (ed.) Generative Perspectives on Language Acquisition. John Benjamins, Amsterdam, pp. 91-129.

Jaeger, T. F. 2008. Categorical data analysis: Away from ANOVAs (transformation or not) and towards logit mixed models. Journal of Memory and Language 59, 434-446. doi: 10.1016/j.jml.2007.11.007.

Jaeger, T.F. 2011. Corpus-based research on language production: Information density and reducible subject relatives. In E. M. Benders \& J. E. Arnold (Eds.), Language from a cognitive perspective: Grammar, usage, and processing. Studies in honor of Tom Wasow. Stanford: CSLI Publications. pp. 161-197.

Kayne, R. 2010. “Why Isn't This a Complementizer?”, in Kayne, R., Comparisons and Contrasts. Oxford University Press New York, pp 190-226.

Kayne, R., Pollock, J.-Y. 2010. Notes on French and English Demonstratives. In Zwart, J.-W. \& de Vries, M. (eds.) Structure Preserved: Studies in Syntax for Jan Koster. John Benjamins, Amsterdam pp. 215-228.

Kidd, E., Brandt, S., Lieven, E., Tomasello, M. 2007. Object relatives made easy: A cross-linguistic comparison of the constraints influencing young children's processing of RCs. Language and Cognitive Processes 22:6, 860-897. doi: 10.1080/01690960601155284.

King, J., and Just, M. A. 1991. Individual differences in syntactic processing: The role of working memory. Journal of Memory and Language 30, 580-602. doi.org/10.1016/0749-596X(91)90027-H.

Lewis, R.L., and Vasishth, S. 2005. An activation-based model of sentence processing as skilled memory retrieval. Cognitive Science 29, 375-419. doi: 10.1207/s15516709cog0000_25.

Lewis, R.L., Vasishth, S., Van Dyke, J.A.. 2006. Computational principles of working memory in sentence comprehension. TRENDS in Cognitive Sciences 10 (10), 447-454, doi:10.1016/j.tics.2006.08.007.

Mak, W., Vonk, W., Schriefers, H. 2002. The influence of animacy on RC processing. Journal of Memory and Language 47, 50-68. doi:10.1006/jmla.2001.2837.

Mak, W., Vonk, W., Schriefers, H. 2006. Animacy in processing RCs: the hikers that rocks crush. Journal 
of Memory and Language 54, 466-490. doi:10.1016/j.jml.2006.01.001.

Rizzi, L. 1990. Relativized Minimality. MIT Press, Cambridge, MA.

Rizzi, L. 2004. Locality and the left periphery. In Belletti, A. (ed.), Structures and Beyond: The Cartography of Syntactic Structures, vol. 3. Oxford University Press, New York, pp. 223-251.

Rizzi, L. 2013. Locality. Lingua. 130. 169-186. doi.org/10.1016/j.lingua.2012.12.002.

Santi, A., and Grodzinsky, Y. 2007. Working memory and syntax interact in Broca's area. Neurolmage 37, 8-17. doi.org/10.1016/j.neuroimage.2007.04.047

Starke, M., 2001. Move dissolves into merge. Doctoral Dissertation. University of Geneva.

Traxler, M., Morris, R., Seely, R. 2002. Processing subject and object RCs: Evidence from eye movements. Journal of Memory and Language 47, 69-90. doi:10.1006/jmla.2001.2836.

Van Dyke, J.A., and McElree, B. 2006. Retrieval interference in sentence comprehension. Journal of Memory and Language 55, 157-166. doi:10.1016/j.jml.2006.03.007.

Van Dyke, J.A., and McElree, B. 2011. Cue-dependent interference in comprehension. Journal of Memory and Language 65, 247-263. doi:10.1016/j.jml.2011.05.002.

Wechsler, D. 2005. Wechsler Individual Achievement Test 2nd Edition (WIAT II). The Psychological Corp., London. 